\title{
RESPONSABILIDADE SOCIAL CORPORATIVA: UM ESTUDO MULTICASOS COM PEQUENAS EMPRESAS DO SETOR SUCROALCOOLEIRO DA REGIÃO DE RIBEIRÃO PRETO-SP
}

\author{
Fabiana de Lima Silva Borges \\ Graduada em Administração pela Faculdade de Orlândia \\ fabianafls@hotmail.com
}

\section{Lesley Carina do Lago Attadia Galli}

Doutora em Administração pela Universidade de São Paulo - USP

Professora de Administração da Faculdade de Ciências Agrárias e Veterinárias - FCAV/UNESP lesleyattadia@uol.com.br

\section{Helenita Rodrigues da Silva Tamashiro}

Doutora em Administração pela Faculdade de Economia, Administração e Contabilidade FEAC/USP. Professora dos Cursos de Administração das Faculdade Reges e de Ciências Gerenciais hrstamashiro@ibest.com.br

\section{RESUMO}

Este trabalho tem como objetivo identificar quais ações ligadas à promoção da responsabilidade socioambiental têm sido adotadas por pequenas empresas fornecedoras do setor sucroalcooleiro da região de Ribeirão Preto/SP. Para tanto, inicialmente, foi realizada uma pesquisa bibliográfica sobre o tema, que permitiu identificar os principais conceitos e tendências sobre o assunto. A pesquisa de campo foi realizada com uma amostra de três pequenas empresas participantes do "Programa TEAR", fomentado pelo Instituto Ethos, já que praticam ações de responsabilidade social. Foi adotado o estudo multicasos como método de investigação e o levantamento de dados operacionalizado por um questionário estruturado com perguntas abertas. Os resultados permitem concluir que a incorporação da responsabilidade socioambiental é um caminho viável para pequenas empresas, pois o investimento nestas práticas promove a sustentabilidade do negócio e retorno para a imagem, além de contribuir para as empresas obterem diferencial competitivo no mercado.

Palavras-chave: Pequenas empresas; Responsabilidade social empresarial; Sustentabilidade.

\section{CORPORATE SOCIAL RESPONSIBILITY: A STUDY WITH SMALL MULTICASE COMPANIES OF THIS SECTOR REGION OF RIBEIRAO PRETO-SP}

\begin{abstract}
The objective of this paper is to identify which of the actions towards promotion of social responsibility have been implemented by small suppliers of the sugar \& ethanol industry of Ribeirão Preto/SP region. To begin this investigation, a bibliographical research on business social responsibility was done, reviewing its historical evolution, the Brazilian panorama, and the main concepts that fulfill the subject. An exploratory and qualitative research study was done with three small suppliers from the sugar \& ethanol industry, participants of the "TEAR Program" promoted by the Ethos Institute. The investigation method adopted is the case study which lead to the development of a questionnaire comprised of open-ended questions. The conclusion is that social responsibility needs to be applied to everyday activities. It also verifies that the incorporation of the socio environmental responsibility is a viable path, that investment promotes the sustainability of the business in the market and also becomes a competitive differential.
\end{abstract}

Keywords: Responsibility social enterprise; Sustainability; Small companies. 


\section{INTRODUÇÃO}

$\mathrm{O}$ atual contexto empresarial tem mostrado que as relações comerciais entre as organizações e seus clientes tornaram-se mais complexas e passaram a exigir novos padrões de competitividade. De fato, segundo Thurow (1997), as forças políticas, econômicas e sociais são responsáveis pela criação de um ambiente mercadológico competitivo e volátil, no qual produtos e serviços deixaram, por si só, de ser fatores de diferenciação para as empresas. De fato, Serpa e Avila, (2006) atestam essa premissa ao afirmarem que o ambiente de negócios, além da busca por níveis maiores de competitividade e produtividade, exige o envolvimento crescente com programas sociais e ambientais. Neste contexto, surgem movimentos, que se opõem ao forte apelo ao consumo dominante, principalmente nos países mais desenvolvidos. As pesquisas sobre o Consumerismo, como é denominado esta tendência (Antonides, Raaji, 1998; Taschner, 2000, Lodziak, 2002, Gomes, 2006) mostram que nas últimas décadas surgiram vários movimentos alternativos (consumo verde, consumo sustentável, ecoconsumo, entre outros) que se colocaram em oposição ao que acreditam ser uma exploração da natureza incompatível com sua capacidade de sustentar a vida no futuro, e que, com isso, compromete as próximas gerações.

Tratam-se de movimentos cujo objetivo é obter mais informação, proteção, leis e garantias para os consumidores, criando um grande desafio para as organizações, obrigadas doravante, não só a gerar lucros para os seus acionistas, mas também, a criar condições para uma gestão socioambiental mais sustentável (desenvolvimento sustentável), trabalhando em conjunto e segundo as necessidades de seus stakeholderes: clientes, fornecedores, empregados, parceiros e colaboradores, a comunidade, o governo, a sociedade em geral (Carrigan, 1995; Durão, 2004).

O desenvolvimento sustentável impõe a preservação dos recursos do meio ambiente a fim de garantir a qualidade de vida das futuras gerações (Alves, Raphaelli; Fangueiro, 2006). Isso significa que ao atuar sob a perspectiva do desenvolvimento sustentável, as organizações devem produzir mais bens e/ou serviços utilizando menos recursos e gerando menos degradação ambiental, não comprometendo, assim, a capacidade das futuras gerações satisfazerem suas próprias necessidades (CMMAD, 1988). Os principais desafios dos setores público e privado para alcançar a sustentabilidade são encontrar soluções para a poluição, a escassez dos recursos naturais e a miséria no mundo (Hart, 1997).

Uma análise crítica das premissas acima permite inferir que as relações comerciais entre as empresas e seus clientes tornaram-se mais complexas e passaram a exigir novos padrões de competitividade, tendo como base atributos que vão além de preço dos produtos, qualidade e suporte pós-venda. Essas drásticas mudanças no processo econômico e produtivo mundial, principalmente a partir da década de 1990, têm contribuído para que o ambiente de negócios se mostre cada vez mais instável e turbulento (Sanches, 2000).

Por esta razão, a questão da qualidade ambiental tem resultado em sérios questionamentos nas diversas atividades que abrangem diversos setores da economia global. Assim, algumas ações vêm gerando debates e recebendo atenção especial das comunidades acadêmica e empresarial nas últimas décadas, no sentido de integrar a RSE ao planejamento estratégico das organizações, especificamente no tocante ao meio ambiente (Motta; Rossi, 2001; Borger, 2001; Thogersen; Olander, 2002; Gilg; Barr; Ford, 2005; Amine, 2003). Nesta nova realidade, as empresas precisam demonstrar uma postura correta, tanto no que diz respeito às leis e aos direitos humanos quanto ao meio ambiente (D'ambrosio, 1998), lançando "produtos ecologicamente corretos" ou "produtos verdes" (Mackenzie, 1990). De fato, o que está em jogo, na opinião de Fortes (1992), não é apenas o combate à poluição, mas todo um processo voltado para a satisfação das necessidades, sem necessariamente comprometer e colocar em risco os direitos humanos no presente e no futuro.

Tais questionamentos têm surgido principalmente nos setores cujo produto final pode provocar impactos diretos no equilíbrio dos ecossistemas (Alves; Raphaelli; Fangueiro, 2006). Outros autores, tais como Gilg; Barr e Ford (2005); Thogersen e Olander (2002) e Amine (2003),

Revista de Gestão Social e Ambiental - RGSA, São Paulo, v. 6, n. 1, p. 70-86, jan./abril 2012. 
advogam que a adoção de tal postura pelas empresas, não é apenas um ajuste com questões de uma legislação específica, mas também uma resposta mercadológica às pressões que grupos de consumidores começaram a exercer, desde o início dos anos 1990, mediante a uma maior preocupação com os aspectos relacionados ao meio ambiente. Para Slack et al (2002), a empresa tem a responsabilidade de não causar danos aos indivíduos, uma vez que o seu negócio é parte integrante de algo mais amplo, que abrange desde a segurança do consumidor, o impacto social e ambiental dos produtos e serviços, segurança dos funcionários, honestidade no relacionamento com fornecedores, etc.

Neste contexto, o movimento da RSE se populariza na comunidade empresarial e criam-se institutos como o Ethos, GIFE, Akatu (Ashley, 2006) para tratar dos aspectos que envolvem a articulação do eixo social do desenvolvimento sustentável. Nota-se certa preocupação em tentar integrar a responsabilidade social ao planejamento estratégico das organizações (Motta; Rossi, 2001) e em entender como as políticas de responsabilidade social podem ser transformadas em ações e projetos capazes de dar sustentação ao modelo de negócios da organização (Wagner, 2003, Gomes, 2006).

Contudo, constata-se que o foco destes estudos tem privilegiado as grandes empresas, sendo o número de trabalhos que se dedicam a estudar a gestão no âmbito das pequenas e médias empresas - PMEs bastante reduzido (Rodrigues; Souza, 2004; Durão, 2004; Corazza; 2003). Alguns estudos foram feitos em outras regiões, mas não na área geográfica selecionada neste estudo, conforme pode ser observado nos trabalhos de Farias e Teixeira (2002); Pinto, Picolotto e Oliveira (2008); Bragato et. al., (2008); Alvarenga e Queiroz (2008).

A implementação de um estudo que contemple a mobilização das PMEs fornecedoras do setor sucroalcooleiro em relação às questões relacionadas ao desenvolvimento sustentável revela-se, portanto oportuna para ampliar mais ainda o debate em torno da RSE (Trevisan, 2002). Outros fatores também justificam tanto a escolha do setor como também do porte das empresas enquanto objeto de estudo: $i$ ) necessidade de se incluí-las na discussão relacionadas às questões socioambientais, tanto pelo fato de possuírem um importante papel econômico quanto social no contexto brasileiro (Longenecker; Moore; Petty, 1997 apud Gomes, 2006); ii) o Brasil, atualmente é considerado por Alvarenga e Queiroz (2008), o maior produtor mundial de cana-de-açúcar. Dos 60 milhões de hectares destinados à agricultura, 5,86 milhões são ocupados pela cana-de-açúcar, o que equivale a, aproximadamente, $10 \%$ do total de tal área. A cada ano, o setor sucroalcooleiro obtém uma maior participação tanto na balança comercial quanto no PIB brasileiro.

Dentro do enfoque apresentado acima, este trabalho se insere no debate sobre o tema da RSE, tendo como foco a observação da postura das pequenas empresas fornecedoras do setor sucroalcooleiro da região de Ribeirão Preto-SP para identificar os tipos de ações adotadas no âmbito da RSE. Com base nessa perspectiva, formulou-se a seguinte questão de pesquisa: Quais as ações voltadas para a promoção da responsabilidade social vêm sendo implementadas pelas pequenas empresas fornecedoras do setor sucroalcooleiro da região de Ribeirão Preto - SP?

Este trabalho está organizado da seguinte maneira: a seguir é apresentado o referencial teórico, contemplando os principais conceitos relacionados ao tema. As seções seguintes trazem, respectivamente, os aspectos metodológicos adotados no estudo e a apresentação e discussão dos resultados encontrados. As considerações finais sintetizam as principais conclusões, apresentam as limitações do estudo e as sugestões para pesquisas futuras.

\section{RESPONSABILIDADE SOCIOAMBIENTAL - RSA: ASPECTOS CONCEITUAIS}

Nos últimos anos, a prática da RSE ou, ainda RSA, vem se consolidando em escala cada vez mais multidimensional e sistêmica no âmbito das organizações, uma vez que a satisfação das necessidades do consumidor parece ser uma peça chave na exploração das oportunidades advindas

Revista de Gestão Social e Ambiental - RGSA, São Paulo, v. 6, n. 1, p. 70-86, jan./abril 2012. 
do movimento ambiental. Ressalta-se que apesar da difusão do termo em nível mundial, o termo responsabilidade social é polissêmico e gera muitas interpretações equivocadas nas diversas áreas acadêmicas. Para Ashley (2005) pode representar obrigação legal, responsabilidade, ou mesmo um dever fiduciário que impõe às empresas um comportamento mais distinto que o do cidadão comum.

Para Melo Neto e Froes (2005) a Responsabilidade Social Empresarial tornou-se parte de um conceito mais amplo: o desenvolvimento sustentável (ou sustentabilidade), o qual é composto por três dimensões: a social, a econômica e a ambiental, sendo a social a mais complexa, pois compreende os seguintes aspectos: direitos humanos, direito dos empregados, direito dos consumidores, direito dos grupos de interesse, envolvimento comunitário, relação com fornecedores, monitoramento e avaliação de desempenho.

No campo científico, conforme é salientado por Dinato (2006), diversas áreas do conhecimento têm, gradativamente, se posicionado em relação às questões socioambientais. Mas o que se entende por responsabilidade socioambiental? A figura 1 procura responder este questionamento ao apresentar os conceitos respaldados por alguns autores, que encaram a questão da responsabilidade social sob cinco abordagens, resumidas no quadro abaixo.

\begin{tabular}{|c|c|}
\hline Autores & Concepção da Responsabilidade Social \\
\hline $\begin{array}{l}\text { Tomei e Lerner } \\
\text { (1997). }\end{array}$ & $\begin{array}{l}\text { É encarada como um "modismo", por se tratar de uma "[...]a forma de comportamento } \\
\text { que é temporariamente adotada por uma proporção identificável de membros de um } \\
\text { grupo social, porque este comportamento escolhido é percebido como socialmente } \\
\text { apropriado para o tempo e para a situação" }\end{array}$ \\
\hline Friedman (1988) & $\begin{array}{l}\text { Como aspectos "liberais, neoliberais e afins", A responsabilidade social do capital, } \\
\text { consiste no uso dos recursos, dedicando-se às atividades destinadas a aumentar seus } \\
\text { lucros até os limites das regras do jogo, o que significa participar de uma competição } \\
\text { livre e aberta, sem enganos ou fraudes. }\end{array}$ \\
\hline Freitas (1997) & $\begin{array}{l}\text { A vista como uma “legitimação social”. Segundo o ponto de vista da autora, as grandes } \\
\text { empresas ou organizações modernas constituem um novo pólo da legitimação social e } \\
\text { como o lugar que pode responder pelo esfacelamento dos vínculos sociais e pelas } \\
\text { questões identitárias que constroem, para e de si, uma autoimagem, capaz de enraizar-se } \\
\text { num imaginário próprio que é repassado, não apenas para os seus membros internos, mas } \\
\text { para a sociedade no seu conjunto. }\end{array}$ \\
\hline Srour (1998) & $\begin{array}{l}\text { É vista como “uma questão ética”. A responsabilidade social está diretamente } \\
\text { relacionada com a questão da ética, ou seja, estão indubitavelmente entrelaçadas, sendo } \\
\text { que esta última reflete o comprometimento com o futuro. }\end{array}$ \\
\hline Drucker (2001) & $\begin{array}{l}\text { É concebida como "responsabilidade social corporativa". Não existe mais ninguém, na } \\
\text { sociedade das organizações, para cuidar da própria sociedade, por este motivo, as } \\
\text { organizações precisam assumir responsabilidade social e agirem de forma responsável, } \\
\text { dentro dos limites da sua competência, sem colocar em risco sua capacidade de } \\
\text { desempenho. }\end{array}$ \\
\hline
\end{tabular}

Figura 1: Abordagens sobre a RSA.

Fonte: As pesquisadoras, a partir dos autores referenciados.

Quanto ao conceito de desenvolvimento sustentável não existe um conceito universal sobre o tema, mas alguns autores brasileiros e estrangeiros têm associado à ideia de sustentabilidade com os aspectos ecológicos, conforme pode ser observado nos trabalhos implementados por Hoffman (2000); Jennings e Zandbergen (1995); Assis (2003). Entre os diversos conceitos encontrados, verificou-se que o mais difundido e, portanto, adotado neste estudo, é respaldado pelo Relatório da Comissão Mundial Sobre o Meio Ambiente e Desenvolvimento - Relatório Brundtland -, cuja premissa é a de que "[...]o desenvolvimento sustentável é aquele que atende às necessidades do presente sem comprometer a possibilidade de as gerações futuras atenderem às suas próprias necessidades". (CMMAD, 1988, p.46).

Buffara e Pereira (2003) advogam que, no Brasil, o conceito de sustentabilidade ou responsabilidade social corporativa começou a surgir com força na década de 1990. A conferência

Revista de Gestão Social e Ambiental - RGSA, São Paulo, v. 6, n. 1, p. 70-86, jan./abril 2012. 
Rio 92, que destacou a questão ambiental como aspecto preponderante da agenda mundial de discussões, e, também, a Campanha contra a Fome (Ação da Cidadania Contra a Fome, a Miséria e Pela Vida), conduzida pelo sociólogo Herbert de Souza, impulsionaram o envolvimento popular e de organizações da sociedade civil durante os anos de 1990. Essa onda de reivindicações referentes a questões ambientais e sociais gerou profundas mudanças no comportamento do cidadão brasileiro. Segundo Lins e Vedra (2007), o desenvolvimento sustentável no âmbito empresarial expressa o conceito do triple bottom line ou do "tripé": economicamente viável, socialmente justo e ambientalmente correto.

Esses três eixos devem ser articulados, de forma equilibrada e interdependente, para que se produzam os resultados econômicos, sociais e ambientais desejados (Abreu, Figueiredo Junior, Varvakis, 2002). Observa-se que, apesar do reconhecimento da necessidade de se trabalhar os três eixos de forma integrada, muitas organizações ainda não conseguem colocar esta filosofia em prática, criando situações de desequilíbrio. Este tem sido um mote interessante, despertando o meio acadêmico para o desenvolvimento de pesquisas voltadas a um melhor entendimento dessa relação de interdependência e do estudo em profundidade da complexidade de cada um dos eixos.

Centralizando essa discussão no eixo social, nota-se que para uma organização conquistar e manter uma imagem positiva no mercado, não basta produzir produtos e serviços com qualidade, gerar empregos e pagar seus impostos em dia; ela precisa, além disso, atuar de forma ética, demonstrando consciência no que diz respeito ao tratamento das questões relacionadas aos colaboradores e clientes e, ainda contribuir de forma efetiva com a minimização dos problemas sociais da comunidade (Ashley, 2006).

Apesar dessa situação, as empresas têm dificuldade em diferenciar a filantropia da responsabilidade social. Na concepção de Araújo (2006), a atuação das empresas em lugares antes ocupados pelo Estado se dá por meio de uma ação filantrópica que, em vez de afirmar o direito dos pobres de sair de sua condição de pobreza, apenas os mantêm sob tutela, esvaziando o sentido político da miséria. Nessa linha, as práticas filantrópicas são pontuais e baseiam-se na doação de recursos e não num projeto coletivo de longo prazo que possa contribuir para erradicar a pobreza ou a exploração sem planejamento dos recursos naturais. Melo Neto e Froes (2005, p.79) afirmam que a filantropia é figurada como o estágio inicial da responsabilidade social, sendo praticada pelos empresários por meio de doações a entidades assistenciais e filantrópicas, sem maior comprometimento. As principais diferenças entre a filantropia e a responsabilidade social, são apresentadas na figura 2 .

\begin{tabular}{|c|c|}
\hline Filantropia & Responsabilidade Social \\
\hline Ação individual e voluntária & Ação coletiva \\
Fomento da caridade & Fomento da cidadania \\
Base assistencialista & Base estratégica \\
Restrita a empresários abnegados & Extensiva a todos \\
Prescinde gerenciamento & Demanda gerenciamento \\
Decisão individual & Decisão consensual \\
\hline
\end{tabular}

Figura 2: Diferenças entre filantropia e responsabilidade social.

Fonte: Instituto Ethos 2001 apud Sousa, 2006.

Os novos tempos exigem uma postura cidadã pelas empresas, ou seja, aquela que se relaciona com a comunidade servindo como fonte indutora de uma nova consciência social que mobilize os dirigentes para uma visão globalizada da humanidade. A seção, a seguir, procura fazer um panorama da gestão da responsabilidade social no Brasil. 


\section{PANORAMA DA GESTÃO DA RSE NO BRASIL}

A revisão da literatura mostra que a partir de 1980, as recentes pressões das organizações ambientais, bem como as discussões acadêmicas acerca do aquecimento global, do efeito estufa, da destruição da camada de ozônio, têm contribuído para levar as pessoas a desenvolverem uma maior consciência ambiental. De fato, segundo Schultz-Pereira e Guimarães (2009), a consciência verde, tem sido incentivada pelos movimentos ambientalistas no sentido de despertar para a necessidade de preservação ambiental e da superação dos diversos problemas causados à natureza. Elkington e Hailes (1989) admitem que todos estão cada vez mais conscientes das ameaças para o ambiente, mas, ao mesmo tempo, advertem que se estamos comprando produtos para simples necessidades ou artigos de luxo, nós estamos a fazendo escolhas que afetam a qualidade ambiental do mundo em que vivemos.

O meio empresarial, parte integrante e ativa dentro dessa realidade, busca formas de melhorar seu relacionamento com o meio ambiente e a sociedade, de modo a contribuir para o desenvolvimento social e econômico, do qual dependem para sua própria sobrevivência, até porque, conforme é colocado por Ottman (1999), um produto ou serviço ecologicamente correto deve ser concebido para satisfazer as necessidades de preservação ambiental de consumidores preocupados com esta questão, levando-se em conta, contudo, de que esta é uma necessidade secundária destes consumidores.

Acompanhando a tendência das economias subdesenvolvidas, no Brasil, a preocupação com a responsabilidade social demorou a sensibilizar empresários e executivos responsáveis pelas decisões estratégicas dos negócios. Esta postura se deve ao processo de industrialização do país acompanhado por um sistema de produção econômica fortemente dependente do Estado (Trevisan, 2002). Assim, segundo este mesmo autor, a responsabilidade social empresarial ganhou força no Brasil e no mundo, principalmente na década de 1990, tendo adesão crescente das empresas, que passaram a considerar o conceito como parte das diretrizes de suas estratégias.

Mintu-Wimsatt e Bradford (1995) acreditam que o aumento de lançamento de produtos "verdes" por parte das empresas, não se trata apenas de um ajuste com as questões de legislação específica, mas também de uma resposta mercadológica às pressões que grupos de consumidores começaram a exercer, desde o início dos anos 1990, mediante a uma maior preocupação com os aspectos relacionados ao meio ambiente. Mohr e Webb (2005) também partilham dessa mesma opinião. Desta forma, a responsabilidade social no ambiente dos negócios, vem se consolidando como uma ferramenta de suma importância para maior aproximação entre os interesses empresariais e a sociedade, envolvendo agentes sociais, organizações públicas, privadas (Ethos, 2009).

Contudo, ressalta-se que no Brasil, a questão da RSE começou a sensibilizar algumas empresas no início dos anos 1990 e ganhou forte impulso ao longo da década, pela ação de entidades não-governamentais e institutos de pesquisa e pelo engajamento da iniciativa privada nas novas políticas sociais do governo (Instituto Ethos, 2009). Nesse contexto, as enormes carências e desigualdades existentes no país, aliadas às deficiências crônicas do Estado no atendimento das demandas sociais, conferem maior relevância à responsabilidade social empresarial. Daí a importância de entidades empenhadas em mobilizar o setor privado em torno do assunto, como a Fundação Abrinq pelos Direitos da Criança, criada em 1990, e o Grupo de Institutos, Fundações e Empresas (Gife), nascido em 1995.

Outra evidência dos avanços obtidos na área, de acordo com Ethos (2009), é o número crescente de empresas brasileiras que vêm obtendo certificados de padrão de qualidade e de adequação ambiental, como as normas ISO. O surgimento de novos parâmetros de certificação relacionados especificamente à responsabilidade social - como as normas SA8000 (relações de trabalho) e AA1000 (diálogo com partes interessadas) - desafia as corporações a atingir um patamar mais alto de desempenho.

Revista de Gestão Social e Ambiental - RGSA, São Paulo, v. 6, n. 1, p. 70-86, jan./abril 2012. 
Ainda no conceito do Ethos (2009), a responsabilidade social empresarial está no centro das discussões das principais economias do mundo e é indissociável do conceito de desenvolvimento sustentável. Citado pela primeira vez em 1987, no relatório da Comissão Mundial sobre Meio Ambiente e Desenvolvimento das Nações Unidas, este termo é definido como o "[...]modelo de desenvolvimento que atende às necessidades do presente sem comprometer a possibilidade de as gerações futuras atenderem às suas próprias necessidades".

O primeiro índice de sustentabilidade empresarial no mercado financeiro foi o Sustainability Index, lançado em 1999 pela Dow Jones, que funciona como indicador para investidores em busca de empresas lucrativas e eficientes na integração dos fatores econômicos, ambientais e sociais nas estratégias de seus negócios.

Ainda de acordo com o Instituto Ethos (2009), a empresa deve utilizar critérios voltados à responsabilidade social na escolha de seus fornecedores, incentivar seus fornecedores e parceiros a aderirem às ações que ela adota perante a sociedade, e exigir certos padrões de conduta nas relações com os trabalhadores e com o meio ambiente. Nesse mesmo contexto, a empresa pode oferecer no seu ambiente, treinamentos a funcionários de pequenos fornecedores, transferindo para eles seus conhecimentos técnicos e seus valores éticos e de responsabilidade social. Para buscar o desenvolvimento econômico da comunidade local, a empresa pode utilizar entidades ligadas à comunidade como fornecedores. Um resumo da evolução das ações da RSE no Brasil é apresentado na Figura 3.

\begin{tabular}{|c|c|c|}
\hline Ano & Entidade & Ação \\
\hline Década de 1980 & $\begin{array}{l}\text { Fundação Instituto de } \\
\text { Desenvolvimento Empresarial } \\
\text { Social (Fides). }\end{array}$ & Lançamento modelo de balanço Social, mas não vingou. \\
\hline 1990 & $\begin{array}{l}\text { Fundação Abrinq } \quad \text { pelos } \\
\text { Direitos da Criança. }\end{array}$ & $\begin{array}{l}\text { Entidade empenhada em mobilizar o setor privado em torno da } \\
\text { responsabilidade social. }\end{array}$ \\
\hline 1995 & $\begin{array}{l}\text { Grupo de Institutos, } \\
\text { Fundações e Empresas (Gife). }\end{array}$ & $\begin{array}{l}\text { Entidades empenhadas em mobilizar o setor privado em torno } \\
\text { da responsabilidade social. }\end{array}$ \\
\hline 2005 & Bovespa & $\begin{array}{l}\text { Índice de Sustentabilidade Empresarial, que reflete o retorno de } \\
\text { uma carteira composta por ações de empresas reconhecidamente } \\
\text { comprometidas com a responsabilidade social e a } \\
\text { sustentabilidade empresarial e atua como promotor de boas } \\
\text { práticas no meio empresarial brasileiro. }\end{array}$ \\
\hline
\end{tabular}

Figura 3: Resumo da evolução das ações de RSE no Brasil.

Fonte: Elaborado pelos autores, com base nas informações do Instituto Ethos (2009).

Após uma análise dos maiores problemas mundiais, a Organização das Nações Unidas (ONU) definiu "Oito Objetivos do Milênio", que foram assinados por meio da Declaração do Milênio por 189 países, em setembro de 2000. No Brasil, esses oito objetivos são chamados de oito jeitos de mudar o mundo: (1) erradicação da pobreza e da fome; (2) universalização do acesso à educação básica; (3) igualdade entre os gêneros; (4) redução da mortalidade infantil; (5) melhoria da saúde materna; (6) combate a AIDS; (7) malária e outras doenças, promoção da sustentabilidade ambiental; e, (8) desenvolvimento de parcerias para o desenvolvimento global.

Quando integramos a empresa na comunidade e valorizamos a participação dos empregados nessa relação, o retorno da empresa melhora sob todos os aspectos. O retorno social institucional ocorre quando a maioria dos consumidores valoriza a atitude da empresa de investir em ações sociais, e o desempenho da empresa obtém o reconhecimento público. A gestão da responsabilidade social no setor sucroalcooleiro é discutida a seguir. 


\section{GESTÃO DA RSE NAS PEQUENAS EMPRESAS DO SETOR SUCROALCOOLEIRO}

Em todo o mundo e, principalmente, no Brasil as micro e pequenas empresas compõem um segmento importante de inclusão econômica e social. O setor tem destacada participação no acesso às oportunidades de emprego e no desenvolvimento econômico do País. Por gerarem grande parte dos postos de trabalho e oportunidades de geração de renda, as micro e pequenas empresas tornaram-se o principal sustentáculo da livre iniciativa e da democracia no Brasil (Silva, 2008).

As empresas pesquisadas são descritas como pequenas empresas de acordo com o seu faturamento, conforme a Lei complementar 123/2006, alterada pela Lei complementar 127/2007 que institui o Estatuto Nacional da Microempresa e da Empresa de Pequeno Porte. A lei define empresa de pequeno porte como o empresário, a pessoa jurídica, ou a ela equiparada, cuja receita bruta em cada ano-calendário seja superior a $\mathrm{R} \$ 240.000,00$ (duzentos e quarenta mil reais) e igual ou inferior a $\mathrm{R} \$ 2.400 .000,00$ (dois milhões e quatrocentos mil reais) (Sebrae, 2009).

Segundo o Serviço Brasileiro de Apoio às Micro e Pequenas Empresa (Sebrae, 2009), as pequenas empresas, no setor de serviços e comércio, possuem entre 10 e 49 funcionários, com faturamento anual de 240 mil até 2,4 milhões, respondem por $98 \%$ das empresas, $67 \%$ das ocupações e $20 \%$ do PIB. Além disso, os pequenos negócios são responsáveis por $95 \%$ dos novos empregos líquidos gerados a cada ano. Ainda, $60 \%$ dos empregos formais estão nas empresas que se encaixam nestes perfis, porém, cerca de $70 \%$ delas desaparecem até o segundo ano de existência. Em geral, as principais causas, entre outras, são as deficiências de gestão empresarial e planejamento.

De acordo com o Ministério de Desenvolvimento, Indústria e Comércio (2003), as micros e pequenas empresas foram responsáveis por $40 \%$ dos salários pagos aos trabalhadores formais, $96 \%$ dos estabelecimentos na década de 1990, das 4,7 milhões de empresas abertas $55 \%$ eram micro empresas, além do que enquanto as grandes aumentaram pouco mais de $2 \%$ as micro e pequenas aumentaram mais de $25 \%$ entre o ano 1995 e 2000. Rodrigues (2007) acrescenta que no cenário dos negócios alguns desafios são bem mais assimilados pelas grandes empresas que contam com maiores condições estruturais e econômicas, porém, este cenário desfavorece as micros e pequenas empresas devido a algumas de suas particularidades, demonstradas na figura 4.

\begin{tabular}{|c|l|}
\hline Característica & \multicolumn{1}{|c|}{ Desvantagem } \\
\hline Estrutura enxuta & Incapacidade de alcançar produção em escala/escopo \\
\hline Porte pequeno & Incapacidade de gerenciar todas as atividades da cadeia de valor \\
\hline Inovação & $\begin{array}{l}\text { Obsolescência de maquinário, devido as condições de crédito } \\
\text { desfavoráveis. }\end{array}$ \\
\hline $\begin{array}{c}\text { Gerenciamento familiar } \\
\text { Atuação em mercados locais e } \\
\text { regionais }\end{array}$ & $\begin{array}{l}\text { Faixa capacitação gerencial, com redução dos horizontes de planejamento } \\
\text { mercado internaçacional. }\end{array}$ \\
\hline
\end{tabular}

Figura 4: Desvantagens associadas às micros e pequenas empresas.

Fonte: Rodrigues, 2007.

A gestão da RSE nas PMEs se torna mais delicada, pois muitas operam no nível da sobrevivência, portanto, neste cenário, pequenas mudanças nas receitas e nos custos podem ser críticas, além dos prazos curtos e do problemático acesso ao capital. Os impulsionadores externos sustentáveis tendem a ser mais fracos, uma vez que essas empresas provavelmente sofrem menos pressão pública que as empresas maiores em demonstrar altos padrões sociais e ambientais. (International Finance Corporation, 2003). O estudo da International Finance Corporation (2003), "Sustentabilidade para Mercados Emergentes", demonstra a existência de um conjunto de oportunidades para as pequenas empresas, com grande foco na redução de custos, assim como no aumento da receita e acesso ao mercado (mais de 40\%). Governança e gestão também contribuíram tanto para a redução de custos quanto para o aumento da receita.

Revista de Gestão Social e Ambiental - RGSA, São Paulo, v. 6, n. 1, p. 70-86, jan./abril 2012. 
No aspecto social, afirma-se que o setor passa por um momento de transformação. A mecanização da colheita da cana acaba com o problema das queimadas, mas gera um corte na oferta de mão de obra. Apesar de ser um trabalho árduo e desgastante, o corte manual da cana-de-açúcar é a fonte de renda de um milhão de trabalhadores. Desde a década de 1970, a renda média dos cortadores aumentou e, atualmente, é de, aproximadamente, $81 \%$ acima do valor do salário mínimo. Isso é fruto de um aumento da quantidade colhida por dia por cortador e não de um aumento efetivo da remuneração (Alvarenga; Queiroz, 2008).

Diante do exposto, pode-se inferir que, os gestores de PMEs saibam responder às demandas relacionadas à responsabilidade social do setor. Além da lucratividade, precisam preocupar-se também com as partes interessadas (stakeholders) e responder às demandas socioambientais emergentes principalmente para manter suas relações comerciais com as grandes corporações empresariais, com o consumidor final e com os mercados externos (Silva, 2008). Desta maneira, a busca de ações que fomentem o desenvolvimento econômico deve passar, necessariamente, por iniciativas que forneçam subsídios para o fortalecimento competitivo das micro e pequenas empresas.

\section{PROCEDIMENTOS METODOLÓGICOS}

O primeiro procedimento foi uma pesquisa exploratória bibliográfica e documental sobre o tema. O objetivo da pesquisa exploratória, segundo Malhotra (2001), é explorar um problema ou uma situação para prover compreensão sobre o tema estudado. Por essa razão, é importante tal realização nos primeiros estágios da investigação (Mattar, 1997; Richardson, 1999). Na segunda fase do estudo, optou-se pela pesquisa de natureza qualitativa, utilizando-se o método descritivo, desenhada por meio de estudo de casos. A opção pela pesquisa qualitativa se justifica pela riqueza dos detalhes obtidos na coleta de dados (Triviños, 1990). Segundo Malhotra (2001) e Mattar (1997), pesquisas qualitativas podem ser desenvolvidas por meio de pesquisa documental, estudo de caso ou etnografia.

Para o tipo de estudo proposto, optou-se pelo estudo multicasos, uma vez que permite uma maior abrangência de resultados (Yin, 2005, Mattar, 1997). O estudo de caso, segundo Yin (2005), constitui uma maneira de se fazer pesquisa empírica que procura investigar fenômenos contemporâneos dentro de seu contexto de vida real, em situações em que as fronteiras entre o fenômeno e o contexto não estão claramente estabelecidas. Mattar (1997) e Godoy (1995) admitem se tratar de uma análise intensiva de um número relativamente pequeno de situações, dando-se ênfase à completa descrição e ao entendimento dos fatores relacionados a cada situação, podendo envolver exame de registros existentes, literatura, observação (participativa ou não) da ocorrência do fato, entrevistas estruturadas, entrevistas não-estruturadas, experiências, entre outros. Neste enfoque, a aplicação de questionários proporciona riqueza de informações que auxilia no alcance dos objetivos estabelecidos, sendo que cada participante tem suas particularidades e visões de negócio diferentes.

A população selecionada neste estudo foi constituída pelas pequenas empresas fornecedoras do setor sucroalcooleiro da região de Ribeirão Preto. Estas empresas participaram do Programa Tear, aplicado no Brasil pelo Instituto Ethos, com apoio do Banco Interamericano de Desenvolvimento (BID) e finalizado em outubro de 2008. O objetivo deste programa foi auxiliar as organizações no fortalecimento da gestão sustentável e na incorporação da responsabilidade social em suas estratégias de negócios com fornecedores e clientes, tornando-os parceiros na construção de uma nova forma de fazer negócio e desenvolvimento sustentável do país (Instituto Ethos, 2009). Sete empresas foram selecionadas para serem respondentes da pesquisa, porém, somente três responderam ao questionário, e seus nomes serão mantidos em sigilo, e serão referenciadas aqui como Empresa A, B e C.

Revista de Gestão Social e Ambiental - RGSA, São Paulo, v. 6, n. 1, p. 70-86, jan./abril 2012. 
Os elementos considerados potenciais para responderem aos questionários foram os executivos das pequenas empresas, envolvidos diretamente no processo de desenvolvimento e implementação de ações de desenvolvimento sustentável dessas empresas. Os elementos selecionados justificam-se por se tratar de um público considerado adequado ao alcance dos objetivos propostos. Tanto a escolha dos elementos quanto da abrangência geográfica, essa é justificada pelas características necessárias à obtenção de casos considerados típicos nessa população, como também pelo fácil acesso da pesquisadora junto aos respondentes potenciais a esses elementos (Mattar, 1997).

A coleta de dados, realizada entre junho e julho de 2009, foi subsidiada por um questionário, constituído por um roteiro de nove perguntas abertas, em razão do caráter qualitativo do estudo e aplicados aos elementos considerados os respondentes potenciais, escolhidos em decorrência da sua representatividade para o objeto de estudo selecionado (Mattar, 1997). Uma das vantagens desse instrumento é que ele pode ser adaptável ao objeto de estudo, aos meios disponíveis para a realização da pesquisa e precisão das informações em termos de grau de exatidão (Gil, 2008). Quanto ao tratamento dos dados obtidos, sua análise e descrição foram realizadas seguindo-se o roteiro das perguntas contempladas no instrumento de pesquisa.

\section{APRESENTAÇÃO E DISCUSSÃO DOS RESULTADOS}

Nesta seção são apresentados os resultados obtidos pela pesquisa de campo, realizada, com os executivos das três empresas selecionadas no estudo. Para visualização e análise dos dados, as informações foram divididas em dois blocos: primeiramente, procurou-se caracterizar o perfil dos respondentes, explicitando a localização das empresas, o ano de fundação, número de funcionários, ramos de atuação, cargo que o respondente ocupa na empresa, grau de instrução e faixa etária, conforme demonstrado na figura 5.

\begin{tabular}{|c|c|c|c|}
\hline & Empresa A & Empresa B & Empresa C \\
\hline \multicolumn{4}{|c|}{ Identificação da empresa } \\
\hline Localização & São Joaquim da Barra & Ribeirão Preto & Ribeirão Preto \\
\hline Ano Fundação & 1890 & 2006 & 1995 \\
\hline $\mathrm{N}^{\mathrm{o}}$ Funcionários & 14 & 290 & 65 \\
\hline Ramo de atuação & $\begin{array}{l}\text { Agricultura, pecuária e turismo } \\
\text { rural }\end{array}$ & \begin{tabular}{|lr} 
Prestação de & serviço da \\
área de & segurança \\
patrimonial &
\end{tabular} & $\begin{array}{l}\text { Comércio } \\
\text { industriais }\end{array}$ \\
\hline \multicolumn{4}{|c|}{ Perfil dos Respondentes } \\
\hline Cargo ocupado & Administrador & Gerente de Projetos & Diretor \\
\hline Escolaridade & Superior completo & Superior completo & Ensino médio \\
\hline Faixa etária & 43 anos & 38 anos & 41 anos \\
\hline
\end{tabular}

Figura 5: Perfil das empresas respondentes (continua).

Fonte: Elaborado pelos autores, a partir dos resultados da pesquisa.

Nota-se também que se trata de empresas sólidas no mercado, tendo em vista que a fundação das empresas A e C já passa dos 10 anos, o que demonstra a capacidade da pequena empresa se manter no mercado, apesar da concorrência. O número de funcionários oscila de acordo com o ramo de atuação, portanto no caso da empresa $\mathrm{B}$, que atua na prestação de serviços, o número de funcionários é bem maior que as demais. E ainda, as pequenas empresas são fornecedoras do setor sucroalcooleiro e cada uma atua em ramos diferentes.

Pelo perfil dos respondentes é possível perceber que a participação no questionário se dá por meio dos seus administradores, proprietários, e possuem grau de instrução de ensino médio e 
superior, ou seja, bom nível de ensino. E a faixa etária dos respondentes é composta por pessoas adultas entre 38 e 43 anos. Sobre as perguntas específicas da pesquisa, a figura 6 traz uma síntese das perguntas contempladas no estudo e as respostas obtidas em cada uma delas.

\section{O que é responsabilidade socioambiental empresarial para você?}

Empresa A: é a forma de gerir ou administrar a empresa que utilizam os pilares econômicos, sociais e ambientais para a tomada de decisões que irão se transformar em ações, que cumprirão a missão da empresa.

Empresa B: entendo por postura ética permanente das empresas não somente no mercado, mas igualmente na sociedade. Não se trata de ações sociais e filantropia, a responsabilidade social, no meu entendimento, deve ser base da gestão.

Empresa C: é uma forma de gestão, a maneira que podemos administrar a empresa com ética e responsabilidade, pensando na empresa no médio e longo prazo, administrar pensando em sustentabilidade.

A empresa participa (ou já participou) de projetos de responsabilidade socioambiental? Qual (is)?

Empresa A: A empresa participou de um programa de capacitação em responsabilidade social empresarial, programa TEAR, durante 20 meses (2007-2008), onde foram repassados os conceitos, ferramentas de gestão em responsabilidade social.

Empresa B: Participa. O projeto ícone da empresa é o apoio para a inclusão de uma disciplina no currículo escolar, que trata de cultura de paz e não violência, doando para os alunos o material didático, e contribuindo com a capacitação dos professores para a inclusão da disciplina.

Empresa C: Já participamos do projeto Tear, agora temos o nosso próprio programa (ELOS - Unindo valores éticos para uma gestão sustentável).

De que maneira a empresa investe em responsabilidade socioambiental?

Empresa A: Algumas ações poderão servir de exemplo como: o investindo em um sistema de produção agrícola orgânico que é o Sistema Agroflorestal; a realizações de reuniões quinzenais com os funcionários (público interno) e; apoiando o projeto Arte na Terra de educação ambiental.

Empresa B: A ação social da empresa vai além da contribuição direta à comunidade. Mobilizamos recursos humanos e financeiros em projetos, com a finalidade de transformar a realidade social brasileira.

Empresa C: Com reuniões semanais para discutirmos nossas ações e implementá-las, podemos dizer também que investimos em uma gestão participativa.

Como surgiu a ideia de investir em responsabilidade socioambiental?

Empresa A: No programa Tear foi onde soubemos o que é responsabilidade social empresarial e como iniciar. Neste programa, também descobrimos que muitas das ações que já realizávamos estavam neste conceito, o que faltava era organizá-las, classificá-las e registrá-las como ações dentro das metas da empresa.

Empresa B: O proprietário da empresa, já trabalha com o tema há vários anos, inclusive auxiliando pequenos, médios e grandes empresários na conscientização do tema, no contexto de gestão.

Empresa C: Quando participamos do projeto Tear tivemos a oportunidade de conhecer os indicadores Ethos, que nos ajudaram muito aprimorar nosso entendimento sobre o tema.

Quais são os objetivos pretendidos pela empresa com as ações de responsabilidade socioambiental?

Empresa A: Desenvolver uma produção diversificada de alimentos e produtos primários com um uso mínimo de energia não-renovável e sem causar poluição/contaminação para o meio ambiente e para o ser humano.

Empresa B: De alguma forma, transformar a realidade social brasileira, e, claro, atingir os objetivos de gestão.

Empresa C: Implementar de fato uma gestão sustentável, tendo como princípio nossos valores, procurando deixar clara a posição da empresa em relação ao tema.

Qual o público-alvo que se pretende alcançar com as ações de responsabilidade socioambiental?

Empresa A: Atualmente, focamos no público interno, os funcionários e o público externo ( comunidade ao redor e os clientes).

Empresa B: A sociedade como um todo.

Empresa C: Colaboradores, clientes, fornecedores, comunidade, governo, concorrente e meio ambiente. A empresa faz acompanhamento das ações de responsabilidade socioambiental que patrocina? Como é feito esse acompanhamento?

Empresa A: Sim, este acompanhamento é feito na gestão das ações, como na ajuda da utilização dos recursos financeiros, e também no acompanhamento dos resultados destas ações, como a satisfação das pessoas que passaram pelo projeto Arte na Terra.

Empresa B: A área responsável pelas ações, Recursos Humanos, acompanha efetivamente e participa

Revista de Gestão Social e Ambiental - RGSA, São Paulo, v. 6, n. 1, p. 70-86, jan./abril 2012. 


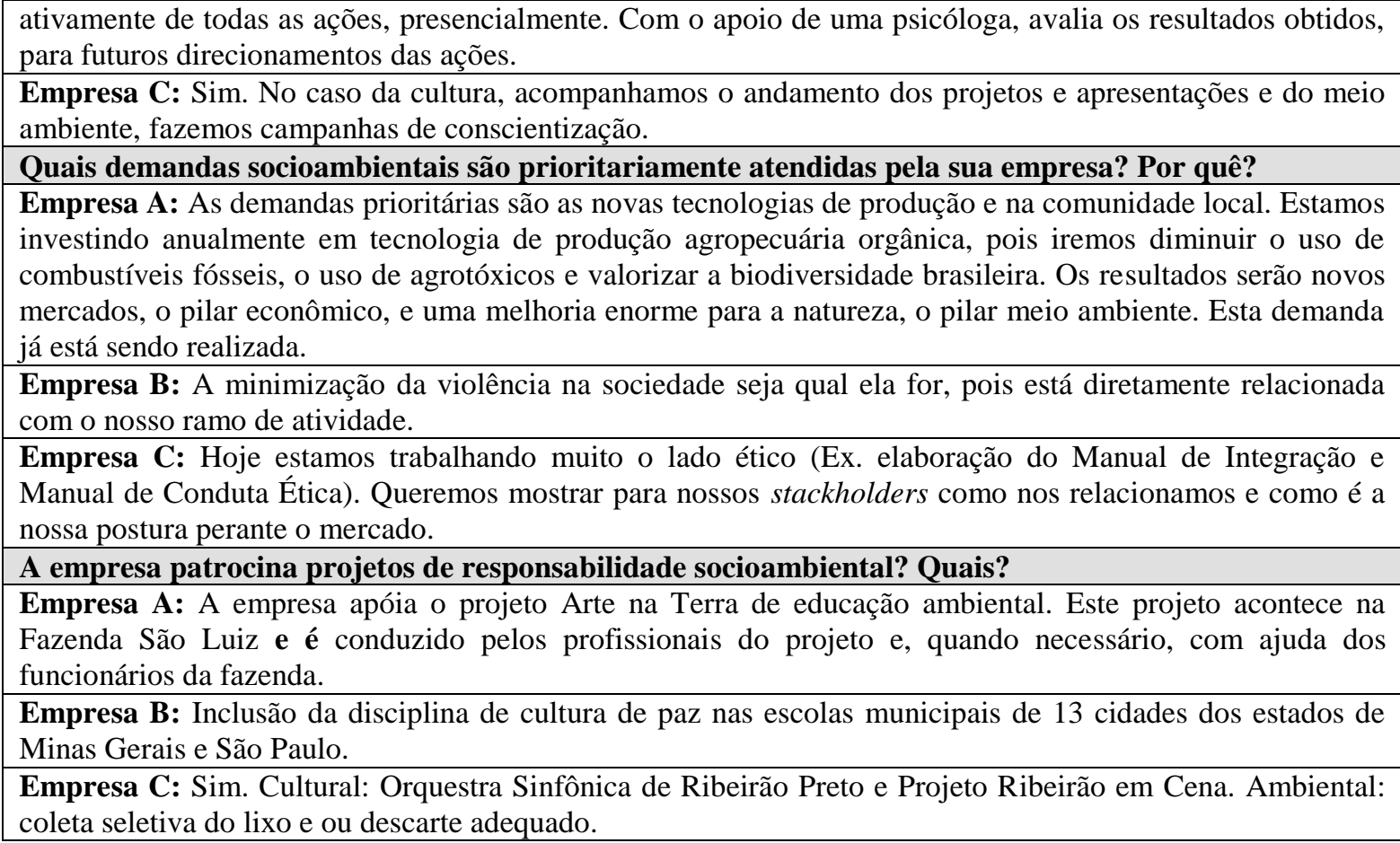

Figura 6: Definição de responsabilidade socioambiental empresarial.

Fonte: Elaborado pelos autores, a partir dos resultados da pesquisa.

Verifica-se, que apesar de não terem definido o conceito de RSE segundo a literatura estudada, os respondentes mostram que conhecem o significado do termo, portanto apresentam traços dos conceitos apresentados anteriormente. A disposição das declarações deixa evidências de que a maioria das empresas sensibilizou-se com a RSE a partir da participação do "Programa Tear", exceto a empresa B que já tem histórico de participação em projetos socioambientais. Observa-se assim, que todas atuam ativamente, participando e desenvolvendo projetos socioambientais, o que parece indicar que têm procurado integrar a RSE às suas ações estratégicas, especificamente no tocante ao meio ambiente, conforme respaldado por Motta e Rossi (2001), Borger (2001), Thogersen e Olander (2002); Gilg, Barr e Ford (2005), Amine (2003), D'ambrosio (1998), Mackenzie (1990). De acordo com a análise dos dados apresentados é possível inferir que as empresas pesquisadas investem no público interno, cada uma com o seu grau de relevância indicando que percebem a importância desse elemento para conseguir bons resultados na gestão.

De um modo geral, nota-se que os objetivos das ações das empresas estão alinhados às metas do milênio: educação básica de qualidade para todos, qualidade de vida e respeito ao meio ambiente. E, portanto, são por elas classificadas com meios de obtenção de bem-estar social, ambiental e econômico. Verifica-se a importância atribuída aos stakeholders, conforme ressalta Carrigan (1995), Durão (2004), Alves, Raphaelli e Fangueiro (2006), mas acredita-se que por se tratar de pequenas empresas, as condições são mais complexas, devido ao maior grau de dificuldades enfrentado por elas em relação às médias e grandes empresas, entre essas dificuldades podemos citar: a dificuldade financeira em viabilizar ações e projetos, a falta de conhecimento para a administração, implantação e acompanhamento das ações e também a falta de incentivo governamental direcionado para as pequenas empresas.

Constata-se que todas as empresas pesquisadas patrocinam projetos de responsabilidade socioambiental. A empresa A, além de patrocinar, participa ativamente no projeto "Arte na Terra", que tem como objetivo promover a educação ambiental para profissionais de qualquer área e estudantes. Todas as empresas pesquisadas relacionam suas prioridades de acordo com seu ramo de atividade, portanto a empresa $\mathrm{A}$, prioriza o meio ambiente, e as empresas $\mathrm{B}$ e $\mathrm{C}$ têm como foco o 
social, pois sua produção não está diretamente ligada ao meio ambiente e sim ao contato com pessoas.

\section{CONSIDERAÇÕES FINAIS}

O objetivo deste trabalho foi identificar os tipos de ações adotadas no âmbito da RSE por pequenas empresas fornecedoras do setor sucroalcooleiro da região de Ribeirão Preto-SP. As ações que as pequenas empresas fornecedoras do setor sucroalcooleiro praticam em sua gestão permitem concluir que as empresas analisadas apresentam pontos fortes e fracos em relação à responsabilidade social. A empresa A destaca-se no âmbito ambiental, mas de acordo com a importância do público interno, esse item apresenta-se como um ponto fraco; a empresa B tem como característica forte a sua participação em projeto de educação e paz, com âmbito na sociedade, tendo como ponto fraco o indicador ambiental e também o público interno, e finalmente a empresa $\mathrm{C}$ tem como ponto forte o indicador valores e transparência, que é bastante evidenciado pela empresa por meio do comportamento ético, mas também apresenta seu ponto fraco no indicador ambiental e no público interno.

Entre as limitações dessa pesquisa destacam-se os poucos trabalhos encontrados sobre responsabilidade social em pequenas empresas do setor sucroalcooleiro. Além disso, a pesquisa é um estudo qualitativo com amostra por conveniência, o que não permite generalização das conclusões. Com isso não é possível concluir que todas as pequenas empresas fornecedoras do setor sucroalcooleiro que recebem instrução e conhecimento sobre o tema, incorporem na sua gestão a responsabilidade socioambiental, porém, a profundidade da análise dos dados obtidos na pesquisa descreve ações que podem ser similares a outras.

Considerando que esta pesquisa analisou apenas três empresas, os resultados abrem a possibilidade de novos estudos: a) estender o estudo a pequenas empresas fornecedoras de outros setores; b) desenvolver uma análise comparativa com as empresas que não concluíram o projeto Tear; e c) pesquisar a participação das grandes empresas no auxílio às pequenas empresas na implementação da Responsabilidade Social Empresarial.

\section{REFERÊNCIAS}

Alvarenga, R. P., Queiroz, T. R. (jul 2008) Caracterização dos aspectos e impactos econômicos, sociais e ambientais do setor sucroalcooleiro paulista. Anais do SOBER - Congresso da Sociedade Brasileira de Economia, Administração e Sociologia Rural, 66. Rio Branco - Acre, 20-23.

Alves, G. J., Silva Da, Raphaelli, N., Fangueiro, R.( 25-30 jul. 2006) Desenvolvimento Sustentável na Indústria Têxtil: Estudo de propriedades e características de malhas produzidas com fibras biodegradáveis. Anais do Congresso Nacional de Técnicos Têxteis, 12 -Fenatêxtil, 8. Recife, Brasil.

Amine, L. S.(2003) An integrated micro- and macrolevel discussion of global green issues: "It isn't easy being green'. Journal of International Management, v. 9, 373-393.

Antonides, G. , Raaij, F. V. (1998) Consumer behaviour: a european perspective. Chichester: John Wiley \& Sons.

Araújo, E. R.(maio 2006) Responsabilidade social empresarial, comunidade e cidadania participativa: um estudo de caso. Dissertação Mestrado (Monografia em Psicossociologia de Comunidades e Ecologia Social) Universidade Federal do Rio de Janeiro, Rio de Janeiro.

Revista de Gestão Social e Ambiental - RGSA, São Paulo, v. 6, n. 1, p. 70-86, jan./abril 2012. 
Ashley, P. (jan.-jun. de 2006) Educação para o consumo ético e sustentável. Revista Eletrônica Mestrado Educacional, v.16.

Ashley, P. (Coordenação). Ética e Responsabilidade Social nos Negócios. 2. ed. São Paulo: Saraiva, 2005.

Assis, R. L.( jan./abr. 2003) Globalização, desenvolvimento sustentável e ação local: o caso da agricultura orgânica. Cadernos de Ciência \& Tecnologia, Brasília, 20(1), 79-96.

Bragato, I.; Siqueira, E. S.; Graziano, G. O.; Spers, E. E.( jan.-abr. 2008) Produção de açúcar e álcool vs. responsabilidade social corporativa: as ações desenvolvidas pelas usinas de cana-deaçúcar frente às externalidades negativas. Gestão \& Produção, São Carlos, 15(1), 89-100.

Borger, F. G.(2001) Responsabilidade social: efeitos da atuação social na dinâmica empresarial. Tese (Doutorado), Faculdade de Economia, Administração e Contabilidade da Universidade de São Paulo, São Paulo, Brasil.

Buffara, L. C. B.; Pereira, M. F. (jan/jul, 2003) Desenvolvimento sustentável e responsabilidade social: um estudo de caso no grupo O Boticário. Revista de Ciências da Administração, 5(9).

Carrigan, M.(1995) Positive and negative aspects of the societal marketing concept: stakeholder conflicts for the tobacco industry. Journal of Marketing Management, v. 11, 469-485.

Cmmad-Comissão Mundial Sobre Meio Ambiente E Desenvolvimento (1988). Nosso futuro comum. Rio de Janeiro: Ed. FGV.

Corazza, R.( jul-dez/2003). Gestão ambiental e mudanças da estrutura organizacional, 1. RAEeletrônica, 2(2).

D’ambrosio, D. (27 de julho de 1998) Investir em ética pode ser um bom negócio. Gazeta Mercantil. São Paulo: Caderno C-8.

Dinato, M. R. (2006) Produção e consumo sustentáveis: o caso da Natura Cosméticos S.A. Tese (Doutorado). Universidade Federal do Rio Grande do Sul. Porto Alegre.

Durão, J. V. (2004) Perfil e panorama atual da responsabilidade social empresarial: uma análise da indústria paulista. Dissertação (Monografia em Economia) Universidade Federal do Rio de Janeiro Instituto de Economia, Rio de Janeiro.

Drucker, P. (2001) Sociedade Pós-Capitalista. São Paulo: Pioneira.

Elkington, J., Hailes, J.(1989) The green consumer guide: from shamppo to champagne - highstreet shopping for a better environment. Londo: Victor Gollancz Ltda.

Farias, J. S., Teixeira, R. M.A (Jan.-Abr. 2002) Pequena e micro empresa e o meio ambiente: a percepção dos empresários com relação aos impactos ambientais. Revista Organização \& Sociedade, $9(23)$.

Fortes, M. (1992) Desenvolvimento e meio ambiente: a visão empresarial. In: Velloso, J. P. R. do. et al. (org.). A ecologia e o novo padrão de desenvolvimento no Brasil. São Paulo: Nobel. 
Freitas, M. E.(1997) Contexto social e imaginário organizacional moderno. In: Encontro Anual da Anpad, 21., Cidade. Anais Eletrônicos do XXI Encontro Anual da ANPAD, 21.

Friedman, M.(1988) Capitalismo e liberdade. (3. ed.) São Paulo: Nova Cultural.

Gil, A. C. (2001) Gestão de pessoas: enfoque nos papéis profissionais. São Paulo: Atlas.

Gil, A. C. Como elaborar projetos de pesquisa. São Paulo: Atlas, 2008.

Gil, A., Barr, S., Ford, N. (2005) Green consumption or sustainable lifestyles? Identifying the sustainable consumer. Futures, v. 37, 481-504.

Godoy, A. S. (maio-jun. 1995) Pesquisa qualitativa: tipos fundamentais. Revista de Administração de Empresas. São Paulo, 35(3), 20-29.

Gomes, D. V. (janeiro/junho de 2006) Educação para o consumo ético e sustentável. Revista Eletrônica Mestrado Educacional, v.16.

Hart, S. L.( Jan-Feb 1997) Strategies for a sustainable world, Harvard Business Review, 75(1).

Hoffman, A.J.(June 2000) Environmental and Social Issues into Corporate Practice, Environment, $42(5), 22$.

Jennings, P. D., Zandbergen, P.A.(1995) Ecologically sustainable organizations: an institutional approach, Academy of Management Review, 20(4), 1015-1052.

Instituto Ethos.(2009) Instituto Ethos de empresas e responsabilidade social nas Empresas O que é RSE ?. $\quad$ Recuperado em 22 abril 2009, de: <http://www1.ethos.org.br/EthosWeb/pt/29/o_que_e_rse/o_que_e_rse.aspx> .

International Finance Corporation (IFC).(2003) Criando valor. O business case para sustentabilidade em mercados emergentes. Primeira edição em português.

Lins, C., Saavedra, R.(Ago.2007) Sustentabilidade corporativa no setor sucroalcooleiro brasileiro. Fundação Brasileira para o Desenvolvimento Sustentável.Rio de Janeiro.

Lodziak, C.(2002) Tne myth of consumerism. London: Pluto Press.

Mackenzie, D. (Dec. 1990) The green consumer. Food Policy.

Malhotra, N. K.(2001) Pesquisa de marketing: uma orientação aplicada. Porto Alegre: Bookman.

Mattar, F. N. (1997) Pesquisa de marketing. (3.ed.) São Paulo: Atlas.

Melo Neto, F. P., Froes, C. A (2005) Administração do terceiro setor. Responsabilidade Social e Cidadania Empresarial: a administração do terceiro setor. 2. ed. Rio de Janeiro, Qualitymark, 1999.

Mintu-Wimsatt, A. T., Bradford, D. M. (1995) In search of market segments for green products. In: Polonsky, M. J., Mintu-Wimsatt, A. T. (Edit.) Environmental marketing: strategies, practice, theory, and researc. Nova Iorque: Haworth. 
Mohr, L. A., Webb, D. J. (2005) The effects of corporate social responsibility and price on consumer responses. The Journal of Consumer Affairs, 39(1), 121-147.

Motta, S. L. S., Rossi, G. B.(dez. 2001) A influência do fator ecológico na decisão de compra de bens de conveniência. Revista de Administração Mackenzie, ano 2, n. 2, 109-130.

Ottman, J. A.( Jul/Aug 1999) Green marketing: Will the consumer pay a premium for green? In Business. 21(4),36.

Pinto, D. S. da., Picolotto, L., Oliveira, L. S. de. (setembro de 2008) Responsabilidade social e ambiental: estudo de caso em uma empresa do ramo eletro industrial. Anais do Congresso Internacional de Administração. Ponto Grossa-PR.

Relatório de Brundtlandnet. (2009) Comissão Brundtland. Recuperado em 22 de abril 2009, de: <http://www.brundtlandnet.com/brundtlandreport.htm>.

Richardson, R. J.(1999) Pesquisa social: métodos e técnicas. (3. ed.) São Paulo Atlas.

Rodrigues, W.C.(2007) Metodologia científica. Fundação de Apoio à Escola Técnica/Instituto Superior de Tecnologia (FAETEC/IST). Paracambi.

Rodrigues, A. M., Souza, L. R. H.(nov. 2004) Desenvolvimento sustentável: a integração entre responsabilidade social de empresas de grande porte e o desenvolvimento econômico de seus pequenos fornecedores. Anais do ENEGEP - Encontro Nacional de Engenharia de Produção. 24 Florianópolis, SC, Brasil, 03-05,

Sanches, C. S.(Jan.-Mar. 2000) Gestão ambiental proativa. RAE - Revista de Administração de Empresas, 40(1).

Sebrae - Serviço Brasileiro de Apoio às Micro e Pequenas Empresas.(2009) Critérios e conceitos para classificação de empresas. Recuperado em 9 de março 2009, de: <http://www.sebrae.com.br/customizado/estudos-e-pesquisa/bia-97-criterios e conceitos>.

Sebrae - Serviço Brasileiro de Apoio às Micro e Pequenas Empresas. Enquadramento das micro $e$ pequenas empresas. Recuperado em 1 de novembro 2009, de: <http://www.sebrae.com.br>.

Schultz-Pereira, J. C.,Guimarães, R. D. (jan./abr. 2009) Consciência verde: uma avaliação das práticas ambientais. REGES - Revista Eletrônica de Gestão, 2(1), 61-73.

Serpa, D. A. F., Avila, M. G.(2006) Efeitos da responsabilidade social corporativa na percepção do consumidor sobre preço e valor: um estudo experimental. Anais do Encontro da ANPAD, 30 de 2327, set. Salvador-BA.

Silva, A. V.(2008) Gestão da responsabilidade social empresarial na micro e pequena empresa. Mestrando em Gestão Integrada em Saúde do Trabalho e Meio Ambiente. Centro Universitário Senac Santo Amaro - SP.

Slack, N. et al.(2002) Administração da produção e operações, São Paulo: Atlas.

Revista de Gestão Social e Ambiental - RGSA, São Paulo, v. 6, n. 1, p. 70-86, jan./abril 2012. 
Sousa, A. C. C. (Setembro/2006) Responsabilidade social e desenvolvimento sustentável: a incorporações do conceito à estratégias empresariais. (Dissertação). Mestrado em ciências em planejamento energético da Universidade Federal do Rio de Janeiro.

Srour, R. H.(1998) Poder, cultura e ética nas organizações. (8. ed.) Rio de Janeiro: Campus.

Taschner, G.B.(abr/jun, 2000) Consumerism and consumers in Brazil. RAE Light, 7(2), 8-11.

Thurow, L.(1997) O futuro do capitalismo: como as forças econômicas moldam o mundo do amanhã. Rio de Janeiro: Rocco.

Thogersen; J., Olander, F.(2002) Human values and the emergence of a sustainable consumption pattern: a panel study. Journal of Economic Psychology, 23, 605-630.

Tomei, P. A, Lerner, A.(1997) Os modismos gerenciais e a dinâmica organizacional. In: Encontro Anual da Anpad, 21., Cidade??? Anais Eletrônicos do XXI Encontro Anual da ANPAD, 21.

Trevisan, F. A. (jul-dez/2002) Balanço social como instrumento e marketing. Revista RAEeletrônica, 1(2).

Triviños, A. N. S. (1990) Introdução à pesquisa em ciências sociais: a pesquisa qualitativa em educação. São Paulo: Atlas.

Wagner, S. A.(2003) Understanding green consumer behaviour: a qualitative cognitive approach. London and New York: Routledge Taylor \& Francis Group.

Yin, R. K.(2005) Estudo de caso: planejamento e métodos, Porto Alegre, Bookman companhia Editora, ( $3^{\mathrm{a}} \mathrm{Ed}$.).

Data do recebimento do artigo: 04/05/2011

Data do aceite de publicação: 09/02/2012 